\title{
«El primer objeto de la policía»: religión y orden público en los bandos de buen gobierno de Cuba (1763-1830)
}

\author{
«El primer objeto de la policía»: religion and public order \\ in the «bandos de buen gobierno» in Cuba (1763-1830)
}

\section{Dorleta APAOLAZA LLORENTE}

Universidad del País Vasco (UPV/EHU)

dorleta.apaolaza@ehu.eus

\begin{abstract}
From the second half of the 18th century onwards, the «bandos de buen gobierno» and «reglamentos de policía» acquired notable development in Hispanic America. In the case of Cuba, and especially of La Habana, each one of the governors during the period from 1763 to 1830 published their own «bando». They were designed to ensure social order and to control the most varied aspects of the daily life of the urban population, even those related to the practice of religion in public spaces. A thorough analysis of these documents allows us to determine the type of connections established by the governor between religion and positive law defended by the Ancien Regime. Moreover, the influence of the new religious paradigm of Enlightened Absolutism can be perceived in the way they tried to standardize the religious practices of an increasingly complex society with strong influences from African culture.
\end{abstract}

Keywords: bando de buen gobierno; Cuba; social control; religión; law.
Resumen: Los bandos de buen gobierno y reglamentos de policía adquieren un notable desarrollo en la América hispana desde la segunda mitad del siglo XVIII. En el caso de la isla de Cuba, y en especial de La Habana, cada uno de los gobernadores del periodo comprendido entre 1763 y 1830 dictó el suyo propio. Destinados a asegurar el control social y a regulador los aspectos más variados de la vida cotidiana de la ciudad, también los relacionados con la práctica de la religión en el espacio público, el análisis detenido y comparativo de estos instrumentos normativos nos permite advertir hasta qué punto y de qué forma el legislador mantiene en este periodo esa estrecha relación entre religión y derecho positivo que se daba en el Antiguo Régimen, así como la influencia del nuevo paradigma religioso del absolutismo ilustrado en el intento de regular las prácticas religiosas de una sociedad urbana cada vez más compleja y, en este caso, fuertemente influida por las culturas de origen africano.

Palabras clave: bando de buen gobierno; Cuba; control social; religiosidad popular; religión.

* Este trabajo forma parte de las actividades del Grupo de Investigación del Sistema Universitario Vasco «País Vasco, Europa y América: vínculos y relaciones atlánticas». 


\section{INTRODUCCIÓN: LOS BANDOS DE BUEN GOBIERNO \\ DEL SIGLO XVIII EN AMÉRICA}

En el marco de las políticas de control social implementadas por el absolutismo ilustrado de la segunda mitad del siglo XVIII en la monarquía hispánica, los bandos de buen gobierno y los reglamentos de policía constituyeron el principal instrumento normativo utilizado por las autoridades locales, especialmente en el mundo urbano en América, para asegurar el orden, vigilar las costumbres, reprimir las malas prácticas sociales y, en definitiva, regular la convivencia y la vida cotidiana de los individuos.

La definición del bando de buen gobierno es compleja, en tanto que no hay en la época una sistematización del corpus legislativo ${ }^{1}$, y su amplio desarrollo geográfico por todo el continente americano adecuándose a la realidad local, los convierte en una herramienta normativa que muestra, en apariencia, gran heterogeneidad. Sin embargo, en la diversidad encontramos elementos comunes que nos posibilitan definir una tipología de bando de buen gobierno ilustrado ${ }^{2}$. Estos no eran sino un mandamiento de la autoridad competente destinado a toda la población de la jurisdicción, con un conjunto de disposiciones de temática local sobre buen gobierno que se daba a conocer públicamente ${ }^{3}$. En el caso de Cuba, aquellos que tuvieran competencia de justicia y policía podían dictarlos, lo que significa que además de los gobernadores de La Habana y Santiago de Cuba, los tenientes de gobernador nombrados por ellos y los alcaldes ordinarios de las villas podían dictar los suyos, aunque tuvieran siempre que respetar el de su superior político, el gobernador respectivo. Esto permitía que la normativa se acomodara a la realidad local, siguiendo la localización propia del derecho indiano ${ }^{4}$. Su marco temporal en la isla caribeña es clara: en la segunda mitad del XVIII vivirán su época de mayor desarrollo, para finalizar en la tercera década del siglo siguiente con el bando del gobernador Dionisio Vives (1823-1832), que apunta ya a lo que será más adelante un cuerpo completo de legislación local ${ }^{5}$.

1 José Joaquín REAL Díaz, Estudio diplomático del documento indiano, Madrid, 1991, p. 205.

2 Cfr. Edda SAMUdio y David J. Robinson, A son de caja de guerra y voz de pregonero. Los Bandos de Buen Gobierno de Mérida Venezuela 1770-1810, Caracas, 2009; Víctor TAU Anzoátegui, Los bandos de buen gobierno del Río de la Plata, Tucumán y Cuyo (época hispánica), Buenos Aires, 2004.

3 Ibid., p. 17.

4 Alejandro AGÜERO, Derecho local y localización del derecho en la tradición jurídica hispana. Reflexiones a partir del caso de Córdoba del Tucumán. El derecho local en la periferia de la monarquía hispana: Río de la Plata, Tucumán y Cuyo. Siglos XVI-XVIII, Buenos Aires, 2013, pp. 91-120.

5 Dorleta APaOlaza Llorente, Los Bandos de buen gobierno en Cuba. La norma y la práctica (17301830), Bilbao, 2016. 
Al ceñirse su temática a aquella considerada de buen gobierno o policía ${ }^{6}$, especialmente en el ámbito urbano, abordan un amplio espectro de asuntos; enmarcados en los intentos de los gobernantes de la época de crear una ciudad ideal, los dos que más peso tenían por regla general eran el orden público y las mejoras urbanísticas ${ }^{7}$. Además se tratan en ellos las cuestiones más comunes de la vida cotidiana de los vecinos, por lo que su estudio nos ofrece una visión rica y detallada de una gran cantidad de aspectos, pero también un espejo donde se advierten las ansias de control y de reforma de las costumbres de los gobernantes ilustrados. Como afirma un autor al tratar del bando de policía para la ciudad de México del virrey Teodoro de Croix, de 1769, «en realidad, más pareciera que la vida de aquella capital, incontenible, se cuela por entre los capítulos del mandato público; transforma al reglamento, le insufla vida $\gg^{8}$. Su carácter impositivo e intrusivo en la vida cotidiana trasluce los intentos del gobernante por reformar la sociedad y sus mecanismos de control. Pero el contraste entre esos propósitos reformadores y la tenaz persistencia de las costumbres y prácticas sociales que se pretenden reformar visualiza la desproporción entre esos objetivos ideales y los escasos medios con que contaba el gobernante para implementarlos, de modo que no consiguieron llevar más allá de la utopía muchos de estos intentos ${ }^{9}$. El reiterado discurso coactivo de carácter moralista típico de estos bandos intentó suplir esa carencia de medios para hacer efectivos los deseos, poniendo de manifiesto la impotencia del mecanismo administrativo y judicial existente ${ }^{10}$.

Uno de los aspectos relevantes de estos bandos es el relacionado con la religión y la práctica de la religión en el espacio público. De ahí que el análisis detenido y comparativo de los bandos de buen gobierno dictados en Cuba entre 1763 y 1830 nos permite advertir hasta qué punto el gobernante-legislador considera

6 Véase ibid., pp. 34-64 sobre el sentido del concepto de policía en la Europa del siglo XVIII y su recepción en la monarquía hispánica; ahí se recoge una amplia bibliografía sobre el tema.

7 Ricardo Angutta CANTERO, La concepción teórica de la idea de ciudad en la Ilustración española: la policía urbana y los nuevos fundamentos de orden, comodidad y aspecto público, en Cuadernos de arte de la Universidad de Granada, 27 (1996), pp. 105-20.

8 Esteban SÁnCHeZ DE TAGLE. Despotismo virreinal en el siglo XVIII. Bando del marqués de Croix del 8 de diciembre de 1769. en Historias, 61 (2005), pp. 113-19.

9 Para mostrar ese contraste es necesario, obviamente, acudir a otras fuentes primarias, sobre todo las procedentes de la actuación de las autoridades locales (gobernadores, corregidores, alcaldes, etc.). Es lo que hacemos en Los Bandos de buen gobierno en Cuba..., pp. 175-306, pero en este trabajo nos limitamos al análisis de los textos de los bandos. Véase también Bettina LAURA SIDY, Crecimiento y control de la vida urbana. Un análisis de los bandos de gobierno en el Buenos Aires colonial (1742-1762), en Cuaderno Urbano. Espacio, Cultura, Sociedad, 10 (2011), pp. 41-61.

10 Francisco TOMÁs y VALIENTE, El derecho penal de la monarquía absoluta (siglos XVI-XVII-XVIII), Madrid, 1969, p. 46. 
la religión como la base del orden social que quiere imponer y, a partir de ahí, en qué medida se mantiene en este periodo esa estrecha relación entre religión y derecho positivo que se daba en el Antiguo Régimen. Por otro lado, se trata de advertir la influencia del nuevo paradigma religioso del absolutismo ilustrado en el intento de regular las prácticas religiosas de una sociedad urbana cada vez más compleja y, en este caso, fuertemente influida por las culturas de origen africano.

\section{EL PENSAMIENTO ILUSTRADO: RELIGIÓN Y DERECHO POSITIVO}

Como decíamos, la religión y las manifestaciones públicas de religiosidad ocupaban un lugar destacado en los bandos. En ellos aparecen al mismo tiempo el mandato de respetar la religión oficial, que se presenta así como base y sustento del poder real, y las manifestaciones de aquella religiosidad que los cubanos practicaban y que la autoridad quería ordenar y controlar. Sin duda, el pensamiento regalista característico de estos gobernantes se trasluce en estos bandos, pero aún más la obligación por «guiar» a los súbditos en la «correcta» vivencia como cristianos y la tajante prohibición de todo aquello que atentara contra la «verdadera religión», como la entendía el nuevo paradigma ilustrado ${ }^{11}$, en especial desde que el aumento de la población de color había traído consigo un crecimiento de los cultos africanos.

El pensamiento ilustrado, en su afán racionalista, cuestionó con fuerza las prácticas religiosas y devocionales que consideraba supersticiosas, irracionales. $\mathrm{La}$ Iglesia que defendían bebía de aquel modelo medieval, supuestamente pobre, no sometida a la curia romana y estrechamente vinculada a la monarquía ${ }^{12}$. Los propósitos reformistas ilustrados se interesaron lo mismo por las formas de vida del clero regular y secular que por las diversas facetas de la religiosidad, lo mismo públicas que privadas, pero especialmente las primeras, en cuanto afectaban al ordenamiento de la vida cotidiana en el espacio urbano y se suponían, a la vez, como la expresión objetiva de la concepción de la religión por parte del pueblo. Si bien algún sector pudo criticar a la Iglesia por haber dejado adulterar la ortodoxia cristiana, nunca se cuestionó a la misma Iglesia o su doctrina, sino que se abogó por un cristianismo más rigorista y austero, intimista y personal, en contraste con la fastuosidad o

11 Teófanes EgIdo LópeZ, La religiosidad de los ilustrados. La época de la Ilustración, en Historia de España. Ramón Menéndez Pidal, Madrid, 1987, pp. 395-435.

12 J. Carlos Vizuete MendozA, Ilustrados y religiosidad popular: Lorenzana, arzobispo en México y Toledo. Religiosidad popular y modelos de identidad en España y América, Cuenca, 2000, pp. 175-214. 
aparato de las manifestaciones de la religiosidad barroca ${ }^{13}$. En palabras de Hazard: «Dios solo podía ser honrado por el culto interior que residía en el alma» ${ }^{14}$. Con esta mentalidad, los ilustrados despreciaron y no comprendieron las formas de religiosidad popular que se habían ido desarrollando entre la población, considerándolas prueba de la ignorancia y fanatismo que la razón debía erradicar ${ }^{15}$. Otras veces, las reformas propuestas perseguían al mismo tiempo objetivos de orden económico, como fue el caso de las cofradías, tan arraigadas en la sociedades hispánicas ${ }^{16}$.

Pero la preocupación por el orden social y público primó en muchas de las decisiones, como en la reforma de las procesiones del Corpus Christi y la Semana Santa que realizó el obispo de La Habana Díaz de Espada (1800-1832), con el apoyo del gobernador marqués de Someruelos, en el contexto de inestabilidad política surgido a consecuencia de la crisis de la monarquía en 1808, que también se dejó sentir en La Habana ${ }^{17}$. Teóricos contemporáneos de renombre son claros a la hora de definir la utilización de la religión por parte del Estado para construir su república, considerando aquella el alma de ésta, al ser un firme apoyo del soberano y un freno para contener delitos y desórdenes por tener un poder disuasorio sobre los individuos superior al coercitivo o punitivo de la autoridad civil y el derecho. En ese contexto debe entenderse la defensa de la «auténtica» religión como pilar básico del orden social ${ }^{18}$.

Aún así, no hay que minusvalorar las razones religiosas que también estaban detrás de las reformas. Los argumentos principales que daba el conde de Aranda en su informe sobre cofradías de 1773, aunque sin quitarle importancia a los aspectos económicos, eran de corte religioso. Frente a la práctica puramente externa de religión que éstas representaban, el conde abogaba por la enseñanza de la doctrina cristiana, por una fe sencilla que potenciara el culto parroquial y por un cambio en la expresión de la religiosidad personal; por ejemplo, fomentado una

13 Jean SarRaILH, La España ilustrada de la segunda mitad del siglo XVIII, México, 1957, pp. 661-707.

14 Paul HaZARD, El pensamiento europeo en el siglo XVIII, Madrid, 1985, p. 106.

15 Teófanes EgIDo LópeZ, La religiosidad de los españoles (siglo XVIII), en Coloquio internacional Carlos III y su siglo, Madrid, 1990, pp. 767-792.

16 Inmaculada ARIAS DE SAAVEDRA ALIAS y Miguel Luis LÓPEZ-GUADALUPE MUÑOZ, La represión de la religiosidad popular: crítica y acción contra las cofradías en la España del siglo XVIII, Granada, 2002, pp. 299-301.

17 Consolación Fernández Mellén, Iglesia y poder en La Habana. Zuan José Díaz de Espada, un obispo ilustrado (1800-1832), Bilbao, 2014, pp. 258-262. Sigfrido VÁZQUEZ CIENFUEGOS, Tan difíciles tiempos para Cuba. El gobierno del marqués de Someruelos (1799-1812), Sevilla, 2008.

18 Concretamente, hablamos de Miguel Ruano y su Tratado sucinto sobre el recurso de injusticia notoria y del grado de segunda suplicación, de 1782. Enrique MARTÍNEZ RUIZ, La seguridad pública en el Madrid de la Ilustración, Madrid, 1988, p. 185. 
verdadera penitencia individual o personal frente a las manifestaciones callejeras, a menudo aparatosas ${ }^{19}$.

Paralelamente, la relación que existía en el antiguo régimen entre el derecho civil y el eclesiástico o canónico irá cambiando paulatinamente. En los siglos XVI-XVII la influencia de la teología escolástica a la hora de fundamentar el ius puniendi real, llevó a identificar delito con pecado, convirtiendo al Estado en el brazo secular de la ley divina positiva ${ }^{20}$. En el siglo ilustrado comienza la secularización del derecho, situando a la razón como la fuente de la ley, al tiempo que iba perdiendo el derecho natural la vinculación teológica que tenía, considerándolo obra de la razón humana y fruto del pacto social. El paralelismo entre delito y pecado que había imperado en época barroca va desapareciendo ${ }^{21}$. Lardizábal define el delito como «las acciones externas, que directa o indirectamente turban la tranquilidad pública o la seguridad de los particulares»; incluso define los delitos contra la religión no como ofensa a Dios sino como actos que perturban el orden social ${ }^{22}$.

Estos cambios podrán apreciarse en los bandos de buen gobierno americanos. Tau Anzoátegui indica cómo, en los que se dictan en el Río de la Plata, la religión y la moral dejaron su impronta, en tanto que el derecho de la época no concebía una actividad ordenadora sin la religión. Aunque no en todos los bandos de buen gobierno americanos se trasluce esta importancia de la religión ${ }^{23}$, en la mayoría de los que se dictaron en Cuba aparecen enunciados y preceptos de carácter religioso y moral, regulando el modo de celebrar las fiestas, velando por el cumplimiento de los deberes sagrados, e incluso se llegan a asimilar conductas asociales con pecados públicos ${ }^{24}$.

19 Miguel Luis LÓPEZ-GUAdalupe MuÑOZ y Inmaculada ARIAS DE SAAVEDRA ALIAS, El conde de Aranda ante la religiosidad popular. Releyendo el informe sobre cofradías de 1773, en José A. FERRER Benimeli, Esteban Sarasa, y Eliseo SERrano (eds.), El conde de Aranda y su tiempo. Congreso Internacional celebrado en Zaragoza, 1 al 5 de diciembre de 1998, Zaragoza, 2000, pp. 631-646. David CARBAJAL LóPEZ, La reforma de las cofradías en el siglo XVIII: Nueva España y Sevilla en comparación, en Estudios de historia novohispana, 48 (2013), pp. 3-33.

20 Francisco Tomás y VAlienTe, El derecho... [ver n. 10], pp. 230-231. Bartolomé Clavero, Delito y pecado. Noción y escala de transgresiones, en Francisco TOMÁs Y VALIENTE et al. (eds.), Sexo barroco y otras transfresiones premodernas, Madrid, 1990, pp. 57-90.

21 Francisco TOMÁs Y VALIENTE, El derecho... [ver n. 10], pp. 85-112.

22 Manuel RIVACOVA Y RIVACOBA, Estudio preliminar: Manuel de Lardizábal o el pensamiento ilustrado en derecho penal en Discurso sobre las penas contrabido a las leyes criminales de España, para facilitar su reforma, por Don Manuel de Lardizábal y Uribe, Madrid, 1782. Edición facsímil de la Fundación Sancho el Sabio, Vitoria, 2001, pp. 11-116.

23 Edda Samudio y David J. Robinson, $A$ son de caja... [ver n. 2]

24 Víctor TAU ANZOÁtegui, Los bandos... [ver n. 2], pp. 68-69. 


\section{RELIGIÓN Y RELIGIOSIDAD EN LOS BANDOS DE BUEN GOBIERNO CUBANOS (SIGLO XVIII)}

El estudio de los bandos de buen gobierno cubanos nos permite trazar una evolución en el modo como los gobernantes de la isla en la segunda mitad del siglo XVIII valoran la religión como la base del orden social que quieren imponer y los mecanismos de control de las prácticas religiosas en el ámbito urbano de la isla. Abrimos la cronología con el «Reglamento para comisarios de barrio» del gobernador conde de Ricla de 1763, que si bien no es un bando de buen gobierno propiamente dicho, fue la norma que rigió por mucho tiempo la actuación de quien era la autoridad local más cercana al vecino en las principales ciudades de la isla, el comisario de barrio, que estableció el mismo Ricla ${ }^{25}$. En esta importante ordenanza local, el respeto y cumplimiento de los preceptos religiosos se definen como «el primer objeto de la policía». Esta relación directa entre religión y orden público o de policía quedaba subrayada en las instrucciones que dio el mismo Ricla a los tenientes de gobernador de sus territorios ${ }^{26}$-también las primeras que se dictaron en $\mathrm{Cuba}-$, donde se aprecia la mentalidad regalista del gobernante. $\mathrm{Si}$ bien el respeto a la Iglesia y al rey van de la mano, las autoridades locales debían asegurar que la jurisdicción eclesiástica no usurpara la real y controlar que las autoridades religiosas cumpliesen con sus deberes y funciones en la sociedad.

Esta relación entre el derecho divino y el positivo o real se mantiene plenamente en el bando de buen gobierno de su sucesor Antonio María Bucareli (1765-1771). Los dos primeros artículos se dedican a advertir y penalizar las actitudes más castigadas por la ortodoxia religiosa, aquellas que atentan contra los sagrados mandamientos, un artículo que se repetirán la mayoría de los bandos de los gobernadores habaneros. En concreto se refiere a la falta de reverencia al Santísimo Sacramento en procesión, la prohibición de blasfemar o jurar, la obligación de venerar a la Virgen y los santos, el respeto a los ministros de la Iglesia y la obligación de santificar las fiestas ${ }^{27}$. Se da por hecho que el conjunto de la población conoce, o debe conocer, esas obligaciones básicas de todo buen cristia-

25 Reglamento de policía publicado por el conde de Ricla el 21 de noviembre de 1763. SEVILLAARCHIVO GENERAL DE INDIAS [=AGI], Santo Domingo, 1378.

26 Instrucción del conde de Ricla a los tenientes de gobernador de Puerto Príncipe, Bayamo y Cuatro Villas para el manejo en los empleos de teniente de gobernador y capitán a guerra. AGI, Santo Domingo, 1157.

27 Bando de buen gobierno de Antonio María Bucareli, del 7 de abril de 1766. AGI, Santo Domingo, 1365 . 
no; su introducción en la normativa local se ha de entender como un recuerdo de su inexcusable cumplimiento, y es muestra evidente de la importancia que seguía teniendo la religión dentro del orden político. De hecho, el respeto al Santísimo, que es la norma que con más detalle se explica, fue uno de los pilares del nuevo espíritu religioso, que quería precisamente reforzar su solemnidad frente a formas inapropiadas (pero muy arraigadas en la población) de culto público. Lo mismo ocurría con la fiesta del Corpus, en tanto que se trata de la celebración y adoración del mismo Dios sacramentado, remarcando la jerarquía con los cultos inferiores y subordinados como los de los santos, reliquias, imágenes, etc. ${ }^{28}$. En la misma línea de hacer respetar el sentido estrictamente religioso de las formas de culto rechazando los excesos barrocos, estaría la prohibición de los artificios de fuego o cohetes voladores en la celebración pública de las fiestas. Como advertían en sus respectivos bandos los gobernadores Navarro (1777-1782) y Unzaga (1782-1785), «las músicas, luminarias y cortinas son demostraciones más serias para las celebridades y no traen los inconvenientes que ocasionan aquellos ${ }^{29}$.

Si bien Bucareli no utiliza un lenguaje excesivamente moralizante y es más genérico a la hora de tratar la materia que algunos de sus sucesores, defendía claramente la subordinación de las autoridades locales no sólo al poder real sino también al gobierno divino (que no al eclesiástico). Esta defensa se aprecia en su proyecto -finalmente rechazado- para reformar el «Reglamento de comisarios de barrio» de Ricla, cuya función principal era precisamente hacer guardar el bando de buen gobierno. En esa propuesta se advertía, de manera más clara que en su bando, cómo el derecho divino y eclesiástico y el derecho real o positivo actuaban en el mismo plano, ya que la autoridad trabajaba al «servicio de Dios y del Rey» y debía hacer cumplir tanto los «preceptos de Dios y de la Iglesia» como las «órdenes reales, bandos y ordenanzas» ${ }^{30}$.

El mismo fundamento aparece de manera clara en el bando de su inmediato sucesor, el marqués de la Torre (1771-1777), cuando en su primer artículo subraya que el objeto principal del rey (es decir, del gobierno), y por tanto de la justicia, es el servicio a Dios y que «sea conocido y adorado en estas regiones a que por la divina bondad ha sido dilatada su Real Corona». Tras dejar bien clara esta indi-

28 Manuel HERNÁNDEZ GONZÁLEZ, La religiosidad popular en Tenerife durante el siglo XVIII: las creencias y las fiestas, La Laguna, 1990, p. 21.

29 Bando de buen gobierno de Diego José Navarro, del 20 de diciembre de 1777. AGI, Santo Domingo, 1418. Bando de buen gobierno de Luis de Unzaga, de 28 de marzo de 1783. MADRIDARCHIVO HISTÓRICO NACIONAL [=AHN], Consejos, 20918.

30 AGI, Santo Domingo, 1378. 
soluble relación, el bando del gobernador se centra, como el de su antecesor, en exigir el respeto debido a los preceptos sagrados ${ }^{31}$.

Esta claridad expositiva para indicar la íntima e indisoluble relación entre el gobierno divino y el del rey queda aún mejor señalada por el gobernador Diego José Navarro (1777-1782), condensando todo su fundamento en la misma introducción de su bando de 1777:

Dios nuestro señor es el principio y fin de todas las cosas y no fueron los hombres criados sino para servirle, adorarle y glorificarle; a este grande objeto miran de lleno los diez mandamientos de la Divina Ley, los cinco de la Santa Iglesia y los tres preceptos del derecho universal a que terminan todas las leyes del reino; es, a saber, vivir honestamente, no hacer daño a otro y dar a cada uno lo que es suyo. En su observancia estriba esencialmente la verdadera felicidad, como en su transgresión está el origen de todas las desgracias. Los pecados públicos excitan la divina indignación y atraen la calamidad sobre los pueblos, por esto viene a ser, en cierto modo, un reo de estado que hace traición a la sociedad civil el que quebranta a la vista de Dios y los hombres aquellos preceptos; y ésta es la razón porque en la Ley treinta y seis, Titulo sexto, Libro tercero de la Recopilación se manda a los corregidores y justicias tengan especial cuidado de castigar los pecados públicos, haciendo ejecutar sin remisión las penas impuestas contra los que los cometieren $(. . .)^{32}$

Navarro establece netamente que el fundamento último de toda ley positiva en el ámbito de la monarquía católica del antiguo régimen sigue siendo la doctrina de la fe. Aún así, aunque la íntima relación entre ley divina y derecho natural esté todavía muy presente, se advierte una cierta evolución en el sentido racionalista ilustrado cuando cita expresamente en el mismo artículo primero los tres preceptos del derecho universal conocidos como las tres máximas de Ulpiano: «vivir honestamente, no hacer daño a otro y dar a cada uno lo que es suyo», que sintetizan el interrogante socrático de como se ha de vivir conforme a la naturaleza ${ }^{33}$. Al referirse expresamente a estos preceptos el gobernador enlaza el derecho divino con el natural y positivo. También podríamos considerar una cierta evolución en este sentido el hecho de que considere necesario regular las costumbres para lograr «la verdadera felicidad»-siempre considerando este término en el sentido ilustrado de

31 Bando de buen gobierno de Felipe de Fonsdeviela, marqués de la Torre, de 4 de abril de 1772. LA HABANA-ARCHIVO HISTÓRICO DE LA CIUDAD DE LA HABANA, Actas capitulares del Ayuntamiento de La Habana, t. 38, anexo. Artículo $1^{\circ}$.

32 Del bando de buen gobierno del gobernador Navarro [ver $\mathrm{n}^{\circ} 29$ ].

33 Susana Isabel EsTRADA, La presencia de los preceptos de Ulpiano en el código de Nüremberg, en Revista General de Derecho Romano, 21 (2013), pp. 1-21. 
la época como progreso económico y social del colectivo además del individuo ${ }^{34}$ como exigencia del orden natural racional, impreso en la naturaleza y en la sociedad humanas por Dios, que dicta sus leyes para preservarlo.

Aún así, puede considerarse que Navarro todavía no nos muestra el concepto racionalista del derecho propio del iusnaturalismo ilustrado en el que, si bien Dios sigue presente, «se reabsorbe en la razón, la razón en la naturaleza y el antiguo derecho divino se convierte en derecho natural y racional $\gg^{35}$. De hecho, en el artículo noveno de su bando, el que pretende regular la actividad de las mujeres públicas o que viven en pecado fuera del matrimonio, considera que no temen «a Dios y a la justicia», manteniendo ese paralelismo entre delito y pecado. Lo mismo cuando trata las faltas más graves contra la ortodoxia religiosa, que describe como «pecados públicos» y por tanto punibles por la autoridad civil, introduciendo entre ellos no sólo comportamientos religiosos, sino también sociales como los que atentaban contra la integridad física de las personas «y las demás cosas que se hicieron visiblemente contra la religión, las leyes y las buenas costumbres». Se advierte también en su bando una concepción regalista e instrumental de la religión, como un medio más, aunque de primer orden, del que se va a servir el Estado en su función pretendidamente civilizadora. De nuevo, las tres máximas de Ulpiano, en este caso cristianizadas.

El gobernador Unzaga, en su bando de 1783, se hace eco de esta relación entre pecado y delito, pero incluye por primera vez, dentro de esa misma relación, un tipo de infracciones que tienen que ver con el incipiente desarrollo de lo que podríamos llamar «opinión pública» en La Habana, al referirse en concreto a «las coplas deshonestas o infamatorias», y «los libelos famosos o pasquines». Cuando todavía no existían más que dos imprentas en la capital, y en principio controladas por el gobierno, esa referencia parece dar fe de que algunos lograban de alguna forma expresar, incluso de forma impresa, manifestaciones de crítica social o contra las personas, una práctica muy difundida entre todas las capas de la sociedad habanera de la época ${ }^{36}$.

Todas las actitudes que se intentan regular en estos artículos se refieren al espacio público, el que más le interesa controlar al gobernante. La autoridad no se entrometerá en temas que corresponden regular a la Iglesia, como las nor-

34 Marc MARTí, El concepto de felicidad en el discurso económico de la Ilustración, en Cuadernos dieciochistas, 13 (2012), pp. 251-70.

35 Paul HAZARD, El pensamiento... [ver n.14], p. 136.

36 Juan B. Amores CARREDANO, Los inicios del periodismo en Cuba: un noticiero manuscrito del siglo XVIII, en Investigaciones históricas, 37 (2017), pp. 296-328. 
mas litúrgicas o las disciplinares del estamento eclesiástico. La salvedad sería la regulación que veremos más delante de las prácticas heterodoxas en las casas particulares relacionadas con los cultos de origen africano. Pero en estos casos, lo que claramente se pretende es controlar a una población en continuo ascenso y con una estructura étnico-social cada vez más compleja que se mostraba reacia a seguir los códigos de conducta que hacen prevalecer el orden público y la paz social tal como lo entienden los ilustrados.

Si Unzaga decide no realizar apenas cambios respecto al de su antecesor, el bando del gobernador Ezpeleta, de 1786, muestra un cambio de mentalidad en el legislador, que comienza a distinguir más claramente entre religión o moral pública y derecho positivo. De hecho, la única referencia directa a la religión aparece también en el primer artículo pero con la escueta afirmación de que «el primer objeto de la real piedad es el servicio de Dios». Al nombrar la real piedad, está subrayando que los mandatos vienen del rey, sin remitirse a la autoridad suprema de Dios para, a continuación, limitarse a recordar que la autoridad real corregirá cualquier incumplimiento en materia de religión o culto. Además, se muestra en estas materias más genérico que sus antecesores y ni siquiera enumera las faltas contra la religión, limitándose a exigir que se deben guardar «las leyes divinas y humanas». Ni siquiera menciona la obligación de reverenciar el Santísimo Sacramento, una de las normas más comunes en los bandos habaneros. Sin embargo, esta variación en el discurso podría deberse al carácter pragmático y positivo de Ezpeleta, como queda también reflejado en la preponderancia que da en su bando a las cuestiones relacionadas con el urbanismo y la seguridad pública, que mostraban un deterioro preocupante debido al crecimiento incontrolado de la ciudad y su entorno ${ }^{37}$.

En estas décadas del siglo XVIII, los bandos publicados por las autoridades locales, los tenientes de gobernador y algunos alcaldes ordinarios, muestran diferencias de criterio respecto a los dictados por el gobernador y capitán general de la isla, en tanto que se ciñen más a las necesidades del ámbito propio, sin entrar, por ejemplo, en argumentaciones o fundamentaciones previas. Obviamente, son más sencillos y con menos pretensiones: su contexto de implantación es más reducido y los recursos de que disponían estas autoridades locales eran muy modestos ${ }^{38}$.

Juan Guemmir y Leonard, teniente de gobernador de la villa de Puerto Príncipe, la segunda en población de la isla, recuerda genéricamente en su bando

37 Bando de buen gobierno de José de Ezpeleta, de 1 de febrero de 1786. AGI, Santo Domingo, 1431. Cfr. Juan B. Amores, Cuba en la época de Ezpeleta (1785-1790), Pamplona, 2000.

38 Circular del gobernador Unzaga junto a su bando de buen gobierno, La Habana, 19 de enero de 1778. AGI, Cuba, 1265. 
de 1772 las obligaciones principales «en el punto de religión» y el deber de la autoridad real de hacerlas cumplir, señalando así, aunque de manera genérica, la estrecha relación entre religión, poder real y cumplimiento de la ley ${ }^{39}$. Otro bando publicado el mismo año por el teniente de gobernador de Trinidad, Ripalda, ni siquiera menciona el tema, pero esto viene más dado por la propia entidad de su bando. En el texto se hace referencia a las leyes que están vigentes, entre las que se encontraría el bando general dictado en La Habana, al que se remite, y centra su contenido en las disposiciones que responden directamente a la realidad local. No falta de todas formas alguna referencia singular, en este caso una indicación sobre el uso del luto entre la población ${ }^{40}$. Como se aprecia, ninguna de las dos autoridades detalla en sus bandos asuntos de índole religioso, ciñéndose más a los propios de la vida local. En realidad, las normas religiosas que hasta entonces habían aparecido en los bandos habaneros eran generales, siendo de obligado cumplimiento aunque no se especificaran en los bandos locales. Por ello, en estas normativas es entendible que se dejaran esas materias para la legislación general, centrando su contenido específico en regular comportamientos propios de la idiosincrasia local que esas normas generales no mencionaban.

Los dos bandos que conocemos de los alcaldes ordinarios de la ciudad de Matanzas, publicados en la década de 1780, muestran en su lenguaje una mayor carga moral y religiosa, en consonancia con los publicados en La Habana por Navarro y Unzaga en 1777 y 1783 respectivamente. En ambos se explican claramente en su primer artículo las obligaciones que «todo fiel cristiano apostólico romano» ha de cumplir, señalando concretamente la reverencia al Santísimo, detallando en este caso la importancia de educar a los jóvenes en este respeto:

Primeramente que todo fiel cristiano apostólico romano es obligado a cumplir sus deberes con obras, palabras y pensamientos empleando lo primero en alabanza y respecto del creador, y lo segundo causando buen ejemplo y edificación a las buenas costumbres que se imprimen en la Juventud, por tanto están todos obligados a reverenciar y acompañar a su divina majestad $(. . .)^{41}$

La última década del siglo XVIII viene marcada por el inicio del auge de la plantación azucarera, proceso que va estrechamente unido a un incremento de la

39 Bando de buen gobierno del 1 de mayo de 1772. AHN, Consejos, 21107.

40 Bando de buen gobierno del 19 de abril de 1772. AGI, Cuba, 1174.

41 Bando de buen gobierno publicado por Simón María Rodríguez y Antonio José de Oria, de 30 de enero de 1784. AHN, Consejos, 20914; y el publicado por Antonio Sandiña y Bernardo del Junco el 31 de enero de 1787. AHN, Consejos, 20923. Concretamente, el primer artículo de sus respectivos bandos. 
población de color por la masiva introducción de mano de obra esclava. Los dos bandos de esta década, el de los gobernadores Luis de Las Casas de $1792^{42}$ y el conde de Santa Clara de $1799^{43}$, marcan un antes y un después en el tratamiento de la religión. Aunque desaparezca de su redacción el lenguaje moralista religioso, aumenta considerablemente el número de artículos destinados a intentar regular las manifestaciones de la religiosidad popular que esos dos mandatarios consideraban necesario erradicar. Si hasta este momento los gobernadores habían dedicado una media de tres artículos a materias religiosas, en estos bandos se aumenta esa cifra hasta los diecisiete artículos y, por primera vez, aparecerán normas que tratan no sólo el ámbito público de las demostraciones religiosas sino también del ámbito privado como las casas particulares. El espíritu moralista ilustrado que busca perseguir todo comportamiento considerado irracional está presente a lo largo de cada uno de esos bandos. Sirva de ejemplo los siete artículos dedicados a regular el juego, o las numerosas referencias a los vagos y mal entretenidos, cuyo comportamiento era considerado peligroso para la consecución no sólo del orden público sino del nuevo sistema social racional que se deseaba implantar.

Aunque escasas, se aprecian algunas diferencias entre ambos bandos como, por ejemplo, una distinción en el tratamiento del culto público debido al Santísimo. Mientras que Las Casas se muestra pragmático y se limita a describir el comportamiento que se ha de mostrar, su sucesor de detiene a aclarar la gravedad del pecado que se pena, no sólo respecto al Santísimo sino también hacia las imágenes de culto: «La reverencia debida al santuario es la primera obligación del cristiano que señala nuestro instituto y en que están de acuerdo las leyes; y habiendo notado algún abuso en materia tan gravísima (...) Se dará a las imágenes el culto que les corresponda». Los dos bandos expresa la parte punitiva en maravedíes, lo que demuestra ser una copia literal de las leyes generales, pues el maravedí no era moneda de uso ni de cuenta en América. El hecho de que el gobernador, en este caso Santa Clara, haya creído necesario rescatar el lenguaje catequético para subrayar la importancia de la norma, podría explicarse por el clima de indiferentismo religioso cada vez más extendido en la isla. Esta preocupación venía ya de mucho antes, pero se agudizó desde los últimos años del siglo XVIII como consecuencia de un conjunto de factores ligados a la mayor apertura comercial desde 1792, que implicó un fuerte incremento de los intercambios de todo tipo

42 Bando de buen gobierno del 30 de junio de 1792. Ejemplar conservado en la Biblioteca Nacional José Martí de La Habana.

43 Bando de buen gobierno del 28 de enero de 1799. LA HABANA-ARCHIVO NACIONAL DE CUBA [=ANC], Asuntos Políticos, leg. 255, exp. 29. 
con colonias y países extranjeros, pero sobre todo a la creciente influencia de las religiones africanas ${ }^{44}$.

En realidad, lo que hacen estos dos gobernadores de final del siglo es convertir en derecho positivo las normas relativas a los cultos africanos contenidas en las constituciones del Sínodo de Santiago de Cuba de 1682, el único de toda la historia colonial de la isla que fue aprobado ${ }^{45}$, añadiendo otras sobre los cabildos de negros.

Entre otras prohibiciones encontramos por primera vez en los bandos -ya estaba en las resoluciones del Sínodo- la de trabajar en los días feriados por la obligación de santificar las fiestas, diferenciando con artículos propios el trabajo de esclavos, el comercio y los artesanos. La redacción de la norma para los primeros es reveladora, en tanto que sólo se prohíbe trabajar en «obras no admitidas por la costumbre», un término lo suficientemente laxo como para que los amos no respetaran la jornada de descanso en periodos de intenso laboreo como la zafra. Los gobernadores quieren hacer cumplir la ley que obligaba a los amos a cristianizar los esclavos; de hecho también se recuerda en sus bandos la obligación de enseñarles el catecismo, tal y como ya aparecía en el Sínodo ${ }^{46}$, pero cedían así a las reticencias de los hacendados a malgastar días u horas de trabajo en la instrucción religiosa ${ }^{47}$.

Otra medida que afectaría a toda la población y que buscaba borrar la falta de ortodoxia religiosa, eran los destinados a regular los altares de cruz u otros santos que se hayan en casas particulares. Esta prohibición ya aparecía en el Sínodo, en el que se impedía cualquier tipo de baile deshonesto, y se detallaba que los altares y nacimientos sólo podían colocarse en templos o en casas de «personas virtuosas y recogidas», pero nunca en otras casas, y se prohibían «músicas, bailes, concurso de gente y otras indecencias» delante de ellos ${ }^{48}$.

En este punto, los bandos diferencian entre los «altares de cruz y otros santos» que pueden encontrarse en las casas y los utilizados en los cabildos de

44 Juan Bosco Amores Carredano y Consolación Fernández Mellén, La Iglesia de Cuba (1760-1830), en Francisco J. CERVANTES, Lucrecia ENRÍQUEZ y Rodolfo AgUIRRE (eds.), Tradición y reforma en la Iglesia hispanoamericana, 1750-1840, México, 2012, pp. 345-385.

45 Sinodo de Santiago de Cuba de 1681, edición e introducción de Antonio García y García, MadridSalamanca, 1982.

46 Ibid., Libro primero, título primero, Constitución VII del Sínodo de Santiago de Cuba de 1681.

47 Javier LaviÑa, Cuba. Plantación y adoctrinamiento, Tenerife, 2007, pp. 116-128.

48 Sinodo de Santiago de Cuba... [ver 43], Libro primero, título segundo, constitución VI: «Para que no haya bailes indecentes, ni en las iglesias, ni casas particulares», y VII: «Que no se formen altares, ni nacimientos en casas particulares en que intervengan bailes y músicas». 
negros. Los primeros eran comunes en la religiosidad popular de la época, y su prohibición aparece no sólo en los Sínodos sino en los reglamentos de policía por materia común cotidiana que eran ${ }^{49}$. En Cuba fueron muy populares, creándose incluso una tradición musical alrededor de los altares y cruces de mayo, herederos de la tradición andaluza. Las coplas que se conservan muestran poca ortodoxia en su contenido, pero a pesar de las reticencias y prohibiciones eclesiásticas, su tradición se mantendría hasta entrado del siglo $\mathrm{XX}^{50}$. En realidad, se está haciendo una lectura de lo decidido en el Sínodo. Si bien en las casas particulares se permiten los altares y se prohíben los bailes que quieren «por este medio de hacer obsequios a la religión que profanan $\gg^{51}$, en los cabildos directamente se da por supuesto que los altares servirán para cultos y bailes blasfemos: no se considera que los cabildos sea una «casa de personas virtuosas y recogidas», porque los levantan para «sus bailes». La diferencia socio-económica se hace evidente cuando la pena monetaria para el delito en los cabildos es menor, tres pesos frente a los seis de los altares, aunque en estos últimos el dueño de la casa iría directamente a la cárcel, si fuera blanco, o a las obras públicas, si fuera de color. Pero también podía ser una aceptación tácita de lo común que podría llegar a ser esta pena en los cabildos de llevarla a cabo con diligencia.

Los cabildos de negros eran organizaciones de tipo étnico-religioso en los que se juntaban las personas de color con fines de ayuda mutua, $\mathrm{y}$ a la vez espacios de sociabilidad de los miembros de las distintas «naciones» o etnias africanas, en los que se compartían elementos de su cultura originaria mezclados con los de la cultura católica hispana. Algunos santos y advocaciones marianas fueron asociados directamente a la simbología de los orishas o deidades africanas ${ }^{52}$. Surgieron desde muy temprano de manera espontánea, y las autoridades se limitaron

49 Así ocurrió en Puerto Rico, donde aparece en El reglamento de policía de 1814, cit. en María Teresa CORTÉS Zavala, Los bandos de policía y buen gobierno en Puerto Rico siglo XIX, en Revista de Estudios Históricos, Universidad de Puerto Rico, 19 (2009-2010), pp. 107-142. En esta isla la celebración fue también muy popular: Ángel LópeZ CANTOS, La religiosidad popular en Puerto Rico (siglo XVIII), Centro de Estudios Avanzados de Puerto Rico y el Caribe, 1993, pp. 50-51.

50 Maximiano Trapero, Religiosidad popular en verso. Últimas manifestaciones o manifestaciones perdidas en España e Hispanoamérica, México, 2011, pp. 602-609.

51 Dentro de la escasa documentación disponible de las autoridades locales cubanas de la época, se encuentran ejemplos de situaciones en las que dichas autoridades tuvieron que intervenir en reuniones de «bailes de negros». Carta de Manuel Cabrera al gobernador Someruelos informando de un «baile de negros» en una casa particular, del 5 de mayo de 1808. AGI, Cuba, 1680.

$52 \mathrm{Al}$ respecto, algunas de las obras consideradas clásicas serían las de Lydia CABRERA, El monte, Letras Cubanas, La Habana, 2009; y Natalia Bolívar ARÓsTEGUi y Reynaldo GONZÁLEZ, Los Orishas en Cuba, La Habana, 1990. 
a tolerarlos como una concesión a la paz social. En teoría, sus miembros debían ser oriundos de África y libres, en contra de las hermandades que sí admitían a esclavos; sin embargo, al estar todos dentro del mismo círculo social, la realidad no era tan hermética ${ }^{53}$. Algunos cabildos estaban asociados a la constitución de cofradías devocionales, que se establecían sobre todo en los conventos franciscanos, la orden con mayor presencia y arraigo en la isla.

Aunque el Sínodo de 1682 ya se refería a ellos a la hora de prohibir las prácticas religiosas sincretistas, no fue hasta 1758 que una real cédula prohibió los cabildos y cofradías de negros fundadas sin real licencia. Es precisamente el bando de buen gobierno del capitán general Luis de Las Casas (1790-1796) donde encontramos el primer corpus normativo destinado a su control ${ }^{54}$. De ahí su trascendencia. En él se enfatizan tres cuestiones: el ya mencionado respeto a los altares, la prohibición del exceso de bailes y música, y la realización de entierros y velorios en las sedes de los cabildos. El baile y la música estaban permitidos en un horario específico para no causar malestar al vecindario, pero se prohibía llevar comida y bebida como si se estuviera realizando una fiesta. La molestia a los vecinos se pone como razón para obligar a los cabildos a cambiar su ubicación fuera de la ciudad, escondiendo el verdadero motivo económico: la revalorización que sufría el reducido suelo intramuros de La Habana. A los cabildos les estaban permitidos sus bailes y danzas en el espacio público ${ }^{55}$, incluso aparecer con sus banderas, pero sólo en días señalados como el día de Reyes ${ }^{56}$, castigando con ocho días de trabajos en obras públicas a los que infringieran la norma.

En ningún caso saldrán los negros por las calles en cuerpo de nación con bandera $\mathrm{u}$ otra insignia, ni para ir a buscar a sus casas a los capataces, ni menos para divertirse tocando sus instrumentos, ni con otro algún motivo o pretexto, y si lo hiciesen, no obstante esta prevención, serán presos y destinados por ocho días al trabajo de obras públicas $^{57}$.

53 María del Carmen Barcia, Los ilustres apellidos. Negros en la Habana colonial, La Habana, 2008, pp. 50-56.

54 Ibid., pp. 118-121.

55 Una mujer negra libre denuncia al comisionado por abuso de poder por haberle pegado y quitado el tambor que estaba tocando en el día de Reyes para pedir «limosna por un ahijado» cuando ella no estaba violando ninguna norma. La autoridad competente considera este hecho un abuso injustificado del comisionado y como tal lo trata. Carta del 16 de enero de 1791 del capitán de partido de Jesús del Monte al gobernador Las Casas. AGI, Cuba, 1471.

56 Fernando ORTIZ, Los negros brujos, La Habana, 2007, pp. 54-57; Roberto SALAS SAN JuAN, Los zancos en el día de Reyes, en Opus Habana 15, 1 (2013), pp. 45-49.

57 Artículo 38 del bando de buen gobierno del gobernador Las Casas, y artículo 37 del bando de buen gobierno del gobernador Santa Clara. 
Los entierros que llevaban a cabo los cabildos también fueron objeto de especial regulación. Los intentos de acabar con los fastos barrocos en las exequias fueron comunes en la época, tanto por parte de las autoridades civiles como las eclesiásticas $^{58}$, pero en el caso cubano sólo se regula el comportamiento de la población de color, al prohibir los velatorios que utilizaban «bailes o llantos al uso de Guinea». Se prohibía directamente el velatorio en los cabildos, dando por supuesto su carácter no cristiano, y en las casas particulares se permitía si se guardaba «la moderación» y no se realizaba ningún tipo de baile. En el caso de ser el difunto un párvulo, se advierte una mayor crítica a este tipo de tradiciones que se traduce en un notable aumento en las penas:

Si con motivo de la muerte de algún parvulito se hiciere algún baile como han acostumbrado las gentes de la ínfima clase, creciendo el desorden hasta el extremo de tener expuesto el cadáver algunos días para continuar en la misma reprehensible diversión ${ }^{59}$.

\section{CAMBIO Y CONTINUIDAD EN LOS ÚLTIMOS BANDOS (SIGLO XIX)}

En las primeras décadas del siglo XIX los bandos siguen la estructura y estilo marcado por el de Santa Clara. De hecho, el primero publicado en este siglo, el del gobernador Someruelos ${ }^{60}$, es en realidad una reimpresión del de Santa Clara con unos añadidos procedentes de los bandos sueltos sobre asuntos urbanos y de policía publicados anteriormente por el mismo gobernador. Entre ellos se encuentran los dictados para velar por la ortodoxia y el orden público en las dos festividades religiosas más importantes de la ciudad: la del patrono San Cristóbal y el día del Corpus. Esta debía prevalecer sobre la primera, como se aprecia claramente en las instrucciones del gobernador, que obliga a embellecer la ciudad con mayor ornato el día del Corpus. Las connotaciones políticas que había tenido esta fiesta en época barroca todavía se mantenían, prueba de ello es la amonestación que realiza el gobernador Someruelos al cabildo de Guanabacoa por haber

58 María José DE LA PASCUA SÁNCHEZ, La solidaridad como elemento del «bien morir». La preparación de la muerte en el siglo XVIII (el caso de Cádiz), en Eliseo SERRANO MARTín (eds.), Muerte, religiosidad y cultura popular: siglos XIII- XVIII, Zaragoza, 1994, pp. 343-64.

59 Artículo 11 del bando de buen gobierno del gobernador Santa Clara y artículo 11 del bando de Luis de Las Casas.

60 Ejemplar conservado en la sección Libros Raros de la Biblioteca de la Universidad de La Habana. 
festejado con mayores fastos a su patrono local que el Corpus ${ }^{61}$. No habíamos encontrado hasta ahora alusiones a estas fiestas en tanto que lo habitual era la publicación de «bandos sueltos» cerca de las fechas señaladas dando las instrucciones pertinentes para llevar a cabo la celebración:

Por cuanto el sábado diez y seis del corriente es la festividad del glorioso mártir señor S. Cristóbal dignísimo patrón de esta muy noble y leal ciudad y como á tal se le deben hacer demostraciones de júbilo y alegría. En cuya atención, mando á todos los vecinos moradores estantes y habitantes de esta ciudad que la noche de su víspera y la de su día pongan luminarias generales en los balcones, puertas y ventanas de sus respectivas habitaciones sin que en manera alguna se hagan fogatas ni candeladas que embaracen el tráfico y diversión del paseo común; igualmente se limpien, aderecen y cuelguen las calles por donde ha de pasar la procesión de la tarde del día diez y nueve con la mayor decencia posible.

Se manda que todas las casas situadas en el tránsito de la procesión de Corpus que ha de salir de la iglesia parroquial mayor se adornen y vistan por sus moradores, con cortinas decentes en los balcones, ventanas y puertas esparciendo flores naturales y ramas olorosas en el suelo que ha de pisar la procesión y expensando los dueños propietarios de dichas casas toldos de bramante de modo que quede cubierta toda la carrera con uniformidad, hermosura y defensa de los ardores del sol durante la función lo cual cumplirán inviolablemente y sin excusa alguna acordándose entre los dueños de las aceras fronterizas para la formación y uso del toldo que fuere común, bajo del apercibimiento de que por su defecto se ejecutará de oficio á costa del inobediente, con mas la pena del duplo de su costo que se le exigirá sin remisión.

Fue también este gobernador quien apoyó al obispo Espada en la reforma de las celebraciones religiosas con el objeto de garantizar la seguridad pública, lo que da un mayor matiz de control a su decisión de publicar e insertar en la recopilación estas normas. Es más, el gobernador Cagigal y Martínez ${ }^{62}$, que publica un bando original siguiendo el estilo y estructura ya fijada por Santa Clara, mantiene la alusión al Corpus Christi, lo que indica la importancia que se dio al significado de esta celebración, no sólo para reafirmar la superioridad del culto del Sacramentado frente a otros cultos menores, sino también porque, en cierto modo, esa fiesta era una representación del poder real. Esta última razón se entiende como reflejo del contexto político de la época: la reinstauración del absolutismo tras las Cortes de Cádiz.

61 Carta del gobernador Someruelos al cabildo de Guanabacoa, La Habana, 5 de octubre de 1807. AGI Cuba, 1633.

62 Bando de buen gobierno del 8 de octubre de 1819. Ejemplar conservado en la Biblioteca Nacional José Martí de La Habana. 
En el mismo contexto político ha de entenderse la novedad de incluir normativa para las escuelas de primeras letras, artículo que ilustra dos cambios importantes en esta época: el desarrollo de estas escuelas y la necesidad de instruir en los valores que la corona consideraba necesarios en una época política convulsa. Concretamente, se detallan las horas semanales que los maestros deben impartir sobre moral pública en las que se debe «inspirar a los niños las santas máximas de nuestra divina religión, la lealtad debida por rodas leyes a nuestro benéfico Soberano y la obediencia y respeto al Gobierno y las autoridades». Esto es, se sitúan en el mismo plano nuevamente la autoridad real y la divina.

Por otra parte, Someruelos también muestra el uso del bando para regular los comportamientos y religiosidad cotidiana al prohibir la tradición que tenían los padrinos de los bautizos de arrojar monedas tras la celebración. Se dan motivos de orden público, ya que realmente está documentado que se llegaban a dar situaciones peligrosas ${ }^{63}$, pero también estaría detrás el velar por un mayor respeto y contención en una ceremonia tan importante como es el sacramento del bautismo.

En el ámbito local, de esta primera década del siglo XIX tenemos el bando publicado en Puerto Príncipe por el teniente gobernador Francisco Sedano en $1811^{64}$. Sedano se muestra muy tajante a la hora de criticar a los que ofenden a la religión, subrayando que un «pueblo cristiano» debe adorar al Santísimo con el mayor respeto y pública reverencia. La adoración al «soberano misterioso» debe mostrarse tal como el «Soberano» católico lo ha dispuesto, «no solo se le rindan las armas, sino que le abatan sus reales estandartes estando en formación». Esto es, el culto al Santísimo no sólo es una obligación del cristiano, sino un mandato del soberano terrenal católico que castigará al negligente. Aunque se haya recuperado un vocabulario religioso moralizante que los gobernadores habaneros habían abandonado en las últimas décadas, ya no queda rastro de la unión entre pecado-delito ni de la dependencia de la autoridad real a la divina, aunque se remarque que la justicia real hará prevalecer el respeto a la primera.

El bando que cierra el periodo, el publicado en 1828 por el gobernador Dionisio Vives ${ }^{65}$, reedita el de Cagigal y Martínez pero lo amplía con nuevos artículos que responden a necesidades específicas que se han dado en el periodo de

63 Buenaventura PASCUAl FerRer, «Sobre los bautizos», en El Regañón de La Havana, martes 2 de diciembre de 1800, en Salvador BUENO, Costumbristas cubanos del siglo XIX, Caracas, 1984, pp. 7-9.

64 Bando de buen gobierno de marzo de 1811. ANC, Gobierno Superior Civil, leg. 1331, exp. 52063.

65 Bando de buen gobierno del año 1828. Ejemplar conservado en la sección de Libros Raros de la Biblioteca de la Universidad de La Habana. 
su mandato. Éstos, como pasaba con Someruelos, no son sino una recopilación de bandos sueltos de la época, de ahí se entiende su carácter apegado a la realidad de hechos concretos. Serán tres: uno dedicado los funerales y entierros, otro al orden público en la Nochebuena tras haberse producido altercados otros años, y el tercero y último dedicado a la celebración de la Semana Santa. La norma sobre funerales no es más que la trascripción de lo decidido por el obispo Díaz de Espada al respecto, defendiendo el nuevo tipo de religiosidad interior, prohibiendo las excesivas muestras de dolor y folclore vistas en los cortejos fúnebres, especialmente los de los africanos, que llevaban los ataúdes abiertos: «por que se ha notado el tumulto, vocería y desorden con que son conducidos en hombros los de color, especialmente siendo de los llamados de nación, acompañados de pelotones de muchos de sus semejantes, sin el decoro y gravedad que se indica». En ninguno se aprecia un lenguaje moralizante, sino un espíritu pragmático que quiere dar respuesta a los problemas surgidos. Sí es reseñable cuando trata la censura en los libros, que califica las «doctrinas democráticas» como «irreligiosas», lo que nos hace recordar el contexto político en el que se ha dictado el bando, la reinstauración del absolutismo tras el Trienio Liberal.

En la otra jurisdicción de la isla, la oriental o de Santiago de Cuba, los bandos de buen gobierno de que tenemos noticia permiten advertir la importancia que tenía también el velar por las buenas costumbres cristianas y el respeto a la religión, pero no nos permiten trazar una evolución tan clara como la que hemos visto en los habaneros. Ni el gobernador Juan Bautista de Vaillant en su bando de 1788 ni su sucesor Juan Nepomuceno de Quintana en el suyo de $1796^{66}$ muestran interés en regular aspectos religiosos: solo dedican a estos asuntos uno de los cerca de treinta artículos de cada bando, copiando la ley de la Recopilación de Indias que penaba con 600 maravedíes el no rendir culto conveniente al Santísimo Sacramento en procesión. Al final del bando, refiriéndose a la obligación de los comisarios de barrio a hacerlo cumplir, ambos remiten a la fórmula utilizada por Navarro haciéndoles responsables ante «Dios y al Rey», pero el no haber regulado ningún aspecto religioso, no hace sino demostrar que copian o reutilizan textos anteriores.

No encontramos razones de fondo que puedan explicar esta diferencia entre estos dos bandos y los coetáneos del gobernador de La Habana, aunque en realidad es significativa, pues no se trata del mismo caso que los tenientes de gobernador ya que, como cabeza del gobierno político de su gobernación, el de

66 Los dos en ANC, Gobierno General, leg. 511, exp. 26389. 
Santiago tenía la competencia de dictar su propio bando de buen gobierno y, al igual que su homólogo habanero, lo remitía a las autoridades de su jurisdicción ${ }^{67}$. Es decir, el bando del gobernador santiaguero era, en principio, independiente del de La Habana, si bien éste le enviaba el suyo para su conocimiento y «por si entre sus capítulos hallase algo digno de que se generalice en la jurisdicción de su mando» ${ }^{68}$. Aunque había algunas diferencias en la estructura de la población -la de color siempre tuvo más peso en el distrito oriental que en el resto de la Isla ${ }^{69}$ - y la sociedad santiaguera muestra un grado de complejidad mucho menor que la de la Habana, las manifestaciones de la religiosidad popular -por señalar uno de los aspectos que más nos interesan ahora- eran prácticamente las mismas. La diferencia podría explicarse quizá porque a estos dos gobernadores le preocuparan sobre todo los aspectos urbanísticos y de orden público, pues la ciudad experimentaba en esa década final de siglo un notable desarrollo que le llevará a cambiar su carácter rural tradicional por otro más urbano y que mostrará más claramente su carácter de capital política del oriente ${ }^{70}$.

Precisamente dos décadas más tarde, en los bandos de Gabriel de Torres y Velasco de $1824^{71}$ y de Francisco Yllas y Ferrer de $1827^{72}$, aparece aquel interés por regular los comportamientos religiosos que echamos en falta en los anteriores. Ambos se enmarcan en la década de reinstauración absolutista de Fernando VII, lo que podría explicar en parte ese cambio. El primero fue el encargado

67 Circulares del gobernador Escudero a las distintas autoridades de la jurisdicción con su bando de buen gobierno.,16 de enero de 1817. ANC, Gobierno General, leg. 511, exp. 26389.

68 Carta del gobernador Unzaga al gobernador de Santiago de Cuba y al teniente de gobernador de Bayamo. La Habana, 19 de enero de 1778. AGI, Cuba, 1265.

69 En la capital santiaguera los blancos siempre estuvieron en minoría respecto a la población de color. Según el censo de 1778, sólo eran blancos el 39\% de los 12.277 habitantes de la ciudad; en 1803 ascendieron hasta el 47\%, como consecuencia de la emigración francesa desde Haití; pero en 1808, tras la salida forzosa de muchos franceses, descendió de nuevo hasta el 33\%, porcentaje que se mantenía veinte años más tarde; la población de color, en todo este periodo, se dividía casi por igual entre esclavos y libres. Juan ANDREO GARCÍA, La conformación de identidades urbanas y procesos de exclusión social: la población de Santiago de Cuba durante el siglo XIX, en L. PROvENCIO GARRIGÓs (ed.), Abarrotes: la construcción social de las identidades colectivas en América Latina, Murcia, 2006, pp. 275-314; Aisnara PERERA DíAZ y Ángeles MERIÑo FuENTES, Familias, agregados y esclavos. Los padrones de vecinos en Santiago de Cuba (1778-1861), Santiago de Cuba, 2011, p. 52.

70 María Elena OrozCO-LAMORE y María Teresa FleITAS-MONNAR, Formation d'une ville caraïbe: urbanisme et architecture à Santiago de Cuba, Pessac, 2011, pp. 36-39; Jacobo DE LA PEZUELA, Historia de la isla de Cuba, vol. 3, Madrid, 1868, pp. 276-278; Olga PORTUONDO ZúÑ̃GA, Santiago de Cuba. Desde su fundación hasta la guerra de los Diez Años, Santiago de Cuba, 1996, pp. 107ss.

71 Bando de buen gobierno del 20 de marzo. ANC, Gobierno General, leg. 566, exp. 28089.

72 Bando de buen gobierno de marzo de 1827. Ejemplar conservado en la Biblioteca Nacional José Martí de La Habana. 
de derogar la Constitución y en su bando, publicado casi al finalizar su mandato, se muestra una vuelta al conservadurismo con una mayor impronta religiosa. Sin embargo, se aleja del lenguaje moralizante utilizando otro más neutro y citando la legislación general, lo que nos remite a la corriente de racionalización del derecho. Pero el gobernador no sólo se limita a las faltas graves que aparecen en las leyes, como el pecado de blasfemia, no santificar las fiestas o no rendir culto convenientemente, sino que incluye artículos específicos y detallados sobre las manifestaciones de religiosidad de la población de color, al estilo de los bandos habaneros de finales del siglo anterior, lo que vendría a ser una prueba de esa mayor complejidad que iba adquiriendo la sociedad santiaguera de que trata la historiografía.

De hecho, si bien como sus antecesores copia la ley que penaliza la falta de veneración al Santuario, introduce la apreciación de que es obligatorio para «el cristiano de cualquiera clase y dignidad que sea», en referencia clara a la numerosa y heterogénea población de color en la villa, con sus cabildos y cofradías, y con una mayor influencia de la religiosidad afrocubana debido a la presencia de muchos -esclavos o libres-procedentes de la cercana Haití ${ }^{73}$. Obviamente, las autoridades santiagueras tuvieron como objetivo principal el buscar mecanismos de control para asegurar la estabilidad social y evitar la influencia de la revolución haitiana ${ }^{74}$. Si bien los esclavos eran mayoría, el porcentaje de libres fue notable, incluso con individuos de cierta importancia a nivel social, por lo que la normativa debía incluir a unos y otros ${ }^{75}$. En este mismo artículo, amplía la veneración a «María Santísima nuestra señora y a las imágenes de los santos», lo que nos remitiría a la Virgen de la Caridad del Cobre, cuyo santuario estaba en su jurisdicción y cuya veneración era ya fuerte en la época, si bien no se tornará en referente central de la religiosidad cubana hasta después de la Guerra de los Diez Años ${ }^{76}$.

Por lo demás, en sus regulaciones sobre la religiosidad popular aparecen en este bando aspectos ya vistos en los habaneros. Se centran claramente en regular los excesos en el culto. Así, se prohíbe arrojar monedas en los bautizos y persigue la profanación de los altares en casas particulares con bailes y música, haciendo en

73 Olga Portuondo Zúñiga, Entre esclavos y libres de Cuba colonial, Santiago de Cuba, 2003, pp. 177ss.

74 José Luis Belmonte Postigo, Ser esclavo en Santiago de Cuba: espacios de poder y negociación en un contexto de expansión y crisis 1780-1803, Aranjuez, 2011, pp. 298-308.

75 José Luis Belmonte Postigo, De esclavos y hacendados. Inmigración etnia y clases sociales en el Oriente de Cuba durante la revolución haitiana, en Lucía PROVENCIO GARRIGÓS (eds.), Abarrotes... [ver n. 69], pp. 185-210.

76 Olga Portuondo ZúNíga, La Virgen de la Caridad del Cobre: símbolo de cubanía, Madrid, 2002. 
esta última una distinción con los cabildos. En estos también se prohibiría realizar funerales con «lloros», aún siendo infante el difunto. Si bien son más escuetos que los de Luis de Las Casas o Santa Clara, o que incluso Cagigal y Martínez a la hora de regular el comportamiento de la población de color, se regula el comportamiento considerado más grave, el de los funerales.

Su sucesor, Francisco Yllas y Ferrer también se muestra apegado a los detalles de la realidad local, a pesar de reducir el número de artículos. Pero dedica el primero a hacer una auténtica profesión de fe, recordándonos el del bando del gobernador Navarro de más de medio siglo atrás:

Dios es el Padre de todos los fieles que le obedecen, que todo lo rige y gobierna según su voluntad: Que es uno en esencia y fuera de el no hay otro: que es eterno no tiene principio, es el principio y fin de todas las cosas, es el Juez de todo el mundo y el que da a cada uno según sus méritos. Dios solo es bueno, Santo, fuerte, justo, piadoso é inmortal, y el que debe ser adorado $(. . .)^{77}$

Este artículo lo podemos considerar, ciertamente, generalista: el gobernador recuerda la obligación de respetar la religión, pero sin querer involucrase en su castigo señala una pena vaga, dejando éste al derecho eclesiástico. El carácter detallista frente a la realidad local que hemos señalado, por tanto, se encontrará en otros que tratan no solo los pecados generales que marcan las leyes, si no aquellos que él aprecia más claramente en la ciudad. En el artículo seis, por ejemplo, contra el lenguaje obsceno inmoral distingue entre la población subalterna, como soldados o esclavos, y los menores de edad, con penas diferenciadas remarcando la obligación de cumplimiento para todo el cuerpo social; pero entre ellas llama la atención la dureza de la destinada a los niños desobedientes, que serían encerrados cuatro días con alimentación restringida. Este detalle puede relacionarse con la importancia que estaba tomando la educación; de hecho se mencionan las escuelas de primeras letras, lo que subrayaría su papel como agentes conformadores de mentalidad y comportamiento ${ }^{78}$. Sin embargo, a pesar del apego por la realidad mostrada por el gobernador, no distingue la religiosidad de la población de color, sólo aparecen cuando se regulan los bautismos y sus

77 Artículo $1^{\circ}$ del capítulo $1^{\circ}$ del bando de buen gobierno del teniente de gobernador Yllas y Ferrer, marzo de 1827, ejemplar conservado en la Biblioteca Nacional José Martí de La Habana.

78 Aunque con menor desarrollo que la capital occidental de la isla, a principios del siglo XIX también las escuelas de primeras letras vivieron una mejora, aunque modesta, en número y en calidad. Ángel HuERTA MARTíNeZ, La enseñanza de primeras letras en Cuba en el siglo XIX (1812-1868), Sevilla, 1992, pp. 85-90. 
desórdenes, prohibiendo que aparezcan niños y negros que se personen para coger las monedas. Puede que el gobernador hubiera decidido confiar más en una normativa específica que no conservamos.

\section{CONCLUSIÓN}

Los bandos de buen gobierno o de policía de los gobernadores de Cuba en la segunda mitad del siglo XVIII y primeras décadas del XIX, a la vez que un instrumento normativo para controlar a la población y asegurar el orden público, constituyen una de las mejores muestras de los intentos del gobernante ilustrado de cambiar mentalidades y reformar costumbres que se consideraban, desde el racionalismo elitista y utópico de esas elites, un serio obstáculo para lograr un orden social civilizado y esa felicidad considerada como el objetivo final del individuo y de la sociedad.

En cuanto formaban parte del cuerpo legislativo -en este caso indiano y localde la monarquía católica, la mayoría de estos bandos, sobre todo los del siglo XVIII, inician su articulado con una declaración expresa relativa a la primacía absoluta de la religión católica y, en su aspecto penal, mantienen la típica relación entre delito y pecado propia del derecho del antiguo régimen. Esta relación irá desapareciendo progresivamente, reservándola en todo caso para los considerados pecados públicos, que son en realidad los que afectan a la jurisdicción del gobernante político.

$\mathrm{Al}$ incidir en los aspectos y manifestaciones públicas de la religiosidad popular, en esta normativa se percibe cómo la reforma de la religión en un sentido racionalista no se ceñía sólo al ámbito religioso, sino que tenía también una significación política: velar por la religión oficial del reino, que era el fundamento del poder regio y del control social. La mentalidad regalista se advierte así en el uso político que se da a algunas normas sobre aspectos religiosos. Esto aparece más claramente cuando se persiguen sobre todo aquellas manifestaciones sincretistas, o simplemente paganas, resultado de a influencia de las creencias que portaba la población de origen africano, muy numerosa en la isla. Finalmente, la nueva religiosidad que se quiere instaurar, más intimista y austera, en contra de la antigua más festiva y barroca, también se trasluce en estos bandos, y es uno de los ejemplos más claros de ese intento utópico de los ilustrados por reformar las costumbres populares. Los teóricos de la época no entendieron la fuerza de la costumbre en la religiosidad y su profundo arraigo y significación para el pueblo. La perduración en el tiempo de muchas de esas expresiones religiosas es la mejor prueba de que aquellos intentos resultaron vanos. 